\title{
FABRICATION OF POLYMER BASED SCHOTTKY DIODE USING PANI/Ag NANO COMPOSITE
}

\author{
Rohini Dhandapani ${ }^{1}$, Senthil Kumar Kandasamy ${ }^{2}$ \\ ${ }^{1}$ Pg Scholar, VLSI Design, Kongu Engineering College, Tamilnadu, India \\ ${ }^{2}$ Assistant Professor, Department of ECE, Kongu Engineering College, Tamilnadu, India
}

\begin{abstract}
Polyaniline nanoparticles were prepared via chemical oxidation method and Silver nanoparticles were chemically synthesized using silver nitrate as major precursor. By using these nanoparticles and PVA, PANI/Ag nanocomposite gel was prepared. The PANI and Ag nanoparticles were characterized separately by using uv-vis spectrophotometer. The prepared PANI/Ag nanocomposite gel was applied on one side of the Al substrate and on the other side of Al substrate, Copper wire was soldered. The electrical characterization of this PANI/Ag nanocomposite Schottky diode was analyzed.
\end{abstract}

Keywords: Absorption, Ag Nanoparticles, Al substrate, Composite, PANI, PVA, Schottky diode

\section{INTRODUCTION}

In recent years, Nanoelectronics seems to be the most promising successor in the field of engineering and electronics. Molecular-scale nanoelectronic devices including diodes, bistable switches and nanowires have been fabricated and characterized in chemistry laboratory. Among these devices considerable attention is given to the fabrication and characterization of Schottky diodes using polymer and metals because Schottky diode offer several advantages over other diodes such as low forward voltage drop, less heat, high efficiency, high current density and low capacitance [14].Among all conducting polymers, polyaniline (PANI) and its derivatives are more attracted because of its chemical stability, simple preparation, high conductivity and low cost [5-7]. Bulk silver shows the highest electrical conductivity among metals at room temperature and it is an adept for producing conducting composites [8,9]. Schottky diode preparation using $\mathrm{PANI} / \mathrm{Ag}$ is another important subject and have great technological importance for wide variety of applications such as Photovoltaic systems, power supply, RF detector etc. [10, 11] Schottky diode invariably requires the use of thermally conductive substrates to manage the heat produced for photovoltaic applications $[12,13]$ and one of the most widely selected materials for this application is aluminum substrate [14]. Moreover, Aluminium is a low cost base material and offer high efficiency [14].

In this work, we synthesized the PANI/Ag nanocomposite gel and it was applied on one side of the $\mathrm{Al}$ substrate and on the other side of Al substrate, Copper wire was soldered because Schottky diode has a Schottky contact between a semiconductor and some appropriate metal and at other end of the semiconductor has an Ohmic contact, with a metal. Then the electrical characterization of PANI/Ag nano composite
Schottky diode was analyzed.

\section{EXPERIEMENTAL SECTION}

\subsection{Materials and Methods}

Aniline and hydrated copper sulphate were obtained from Merck, Germany were the major precursors to synthesize polyaniline nanoparticles. Silver nitrate $(\mathrm{AgNO} 3)$ and sodium citrate were the major precursors to synthesize silver nanoparticles in the range of $10 \mathrm{~nm}$ approximately. All supplementary chemicals were of analytical grade and solutions were prepared with mili-Q water.

\subsection{Preparation of PANI Nanoparticles}

Aniline $(20 \mathrm{~mL})$ was added in a $150 \mathrm{~mL}$ beaker containing 60 $\mathrm{mL}$ of methanol. The solution in a beaker was stirred on a magnetic stirrer for $45 \mathrm{~min}$ to make a homogenous solution at constant temperature. To this solution, $20 \mathrm{~mL}$ of $0.05 \mathrm{M}$ aqueous copper sulphate solution was added drop by drop with constant stirring on magnetic stirrer at same temperature. After $30 \mathrm{~min}$ opaque blue solution was obtained and at the end of the reaction (after $45 \mathrm{~min}$ ), the dark green color solution was yielded. The solution was filtered and dried and at the end dark green particles (polyaniline) were obtained [15].

\subsection{Preparation of Ag Nanoparticles}

Silver nanoparticles were prepared by a citrate reduction method. $4.5 \mathrm{mg}$ of silver nitrate was dissolved in $100 \mathrm{~mL}$ of $\mathrm{H} 2 \mathrm{O}$ and brought to boiling. $2 \mathrm{~mL}$ of $1 \%$ sodium citrate solution was added. The solution was kept on boiling for $1 \mathrm{hr}$. During this process solution was mixed vigorously. Solution was heated until color change was evident (light brown). Then it was removed from the heating element and stirred until it 
was cooled to room temperature. The obtained solution was filtered and dried. At the end silver nanoparticles were obtained [16].

\subsection{Preparation of PANI/Ag Nano Composite gel}

The PANI particles of $2.5 \mathrm{mg}$ and silver nanoparticles of $2.5 \mathrm{mg}$ was dissolved in $100 \mathrm{~mL}$ of methanol and brought to stirrer. Then the solution was stirred on the magnetic stirrer for 20min. At the end, PANI/Ag solution mixture was obtained. The polyvinyl alcohol was added to the prepared PANI/Ag mixture and stirred on the magnetic stirrer for 2 hours. At the end of the reaction PANI/Ag nanocomposite gel was obtained $[7,17]$.

\subsection{Fabrication of a Schottky diode}

The PANI/Ag nano composite was deposited at one side of the Al substrate for Schottky contact and the wire drawn from the PANI/Ag side was attached to it by PANI/Ag nano composite gel. The Ohmic contact was to be made of copper wire solder. The Schottky diode using PANI/Ag nano composite was shown in Fig 1.

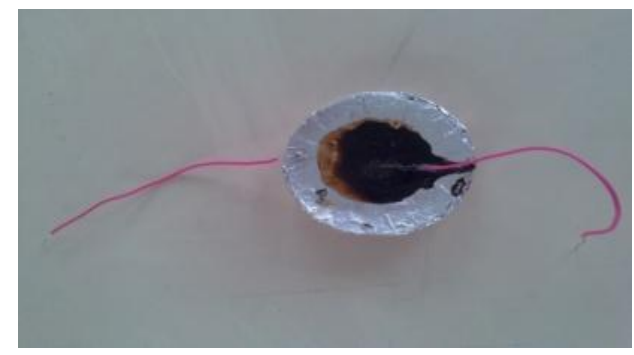

Fig -1: Schottky diode using PANI/Ag nanocomposite

\section{RESULTS AND DISCUSSION}

\subsection{UV-VIS Spectra}

UV-VIS characterization gives the absorption spectra in Ultra Violet - Visible spectral and near infrared region. This measurement gives the absorption spectra for the prepared PANI nanoparticles and Silver nanoparticles. The absorption spectra for the above two materials are shown in Fig 2 and Fig 3 respectively. Optical absorbance spectra in the regions (300 $-600 \mathrm{~nm}$ ) were recorded at room temperature using UV-VIS spectrophotometer 119. The absorption peak was occurred at $335 \mathrm{~nm}$ and $405 \mathrm{~nm}$ for PANI dispersed in methanol [9]. Similarly for silver nanoparticles the peak was occurred at 410 $\mathrm{nm}[9,18,19]$.

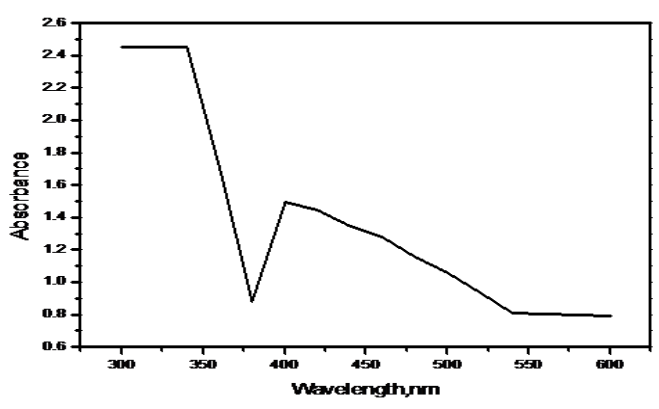

Fig -2: Absorbance spectra for PANI

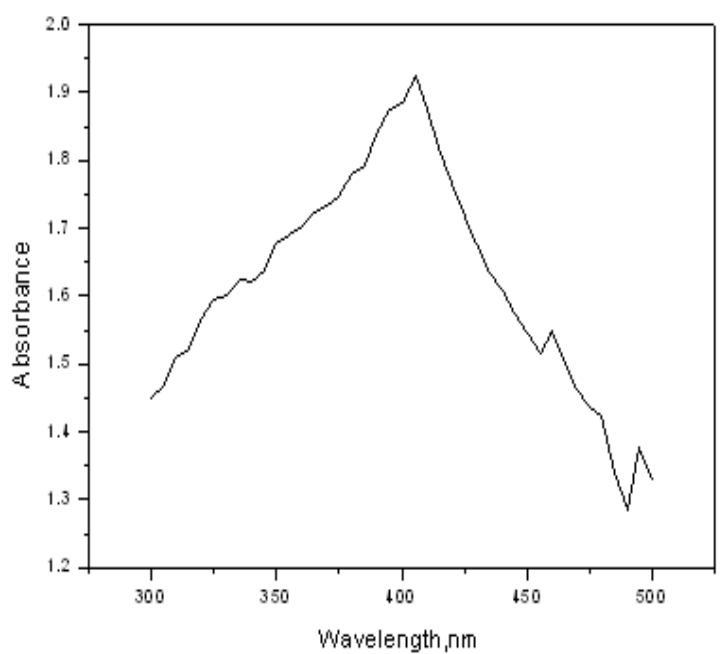

Fig -3: Absorbance spectra for Ag nanoparticles

\section{ELECTRICAL CHARACTERIZATION}

\subsection{Current Voltage Characteristics}

The circuit which was implemented for the current- voltage characteristics of the Schottky diode is shown in Fig 4. The circuit with the Schottky diode was made on the breadboard, voltage source, Multimeter, Ammeter, wires, Resistor were the other requirements shown in Fig 5.The I-V characteristics of the PANI/Ag nano composite Schottky diode (Fig 6) shows that current flow in one direction is definitely favoured over the other. We can roughly say that sans the series resistance the Voltage drop across the diode would have been $0.12 \mathrm{~V}$. The resistance changes with temperature. So at higher voltages when there is substantial heating, the current reading gradually goes up, for ( $>5$ minutes at $5 \mathrm{~V}$ forward bias) indicating that the resistance is lowered [20]. If the current is switched off for some time, the resistance returns to its room temperature value. So when switched on again, the current returns to its low starting value. It is noted that the resistance of $3000 \mathrm{ohms}$ 
is quite high in comparison to normal diodes and the power dissipation of $4.8 \mu \mathrm{w}$ is low in comparison to normal diode.

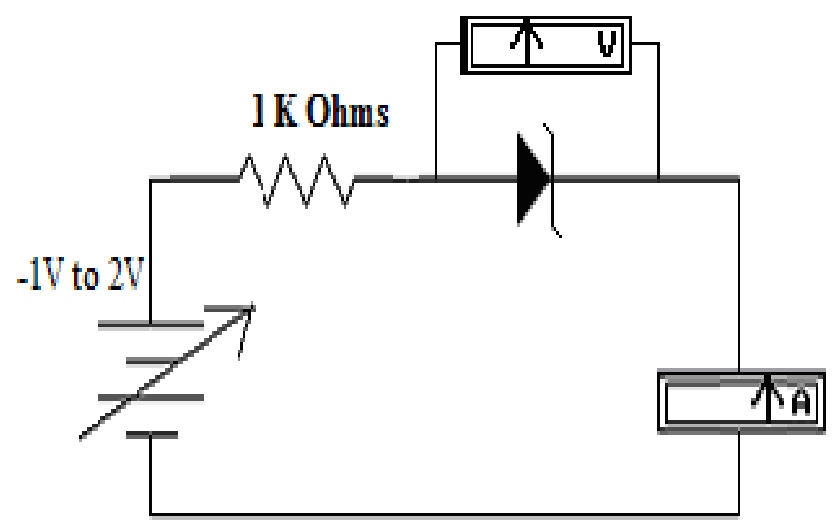

Fig -4: Schottky diode I-V characteristics circuit diagram

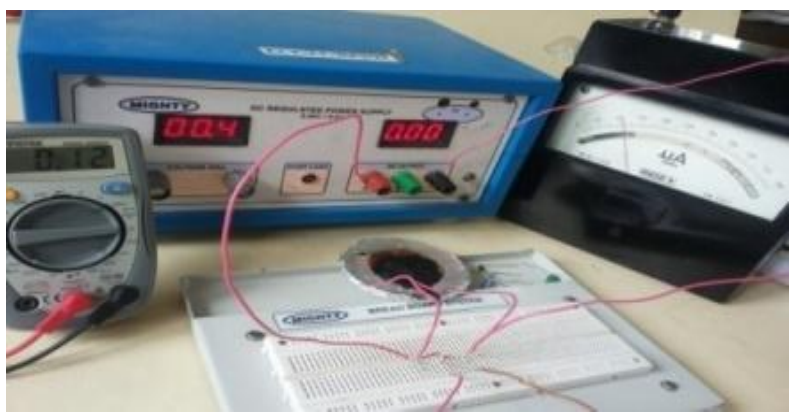

Fig -5: Schottky diode I-V characteristics circuit set-up

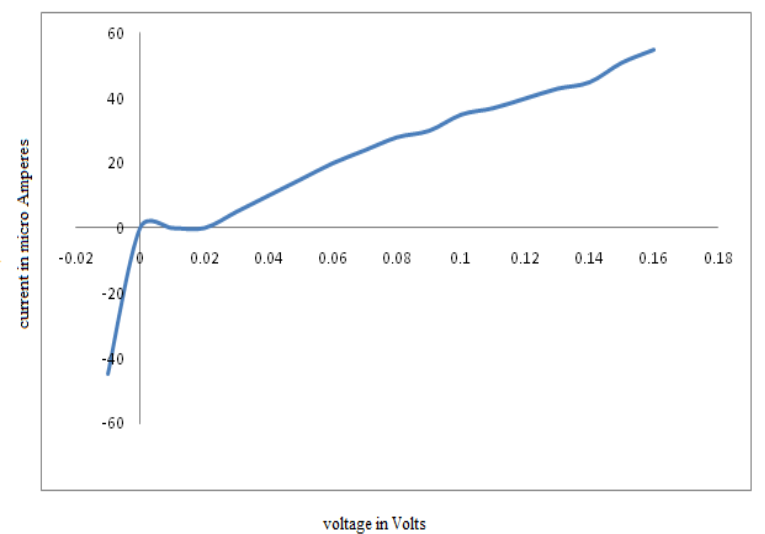

Fig -6: current vs voltage characteristics in both Forward reverse regions.

From Fig 6,

$>$ Forward voltage drop, $\mathrm{V}_{\mathrm{F}}=0.12 \mathrm{~V}$

$>$ Forward current, $\mathrm{I}_{\mathrm{F}}=40 \mu \mathrm{A}$

$>$ Resistance of the diode $=3000 \mathrm{ohms}$
Power Dissipation of the diode $=4.8 \mu \mathrm{W}$

\subsection{Voltage Characteristics on Application of Square}

\section{Wave Pulse}

The circuit which was implemented with the use of a Function Generator at $2.2 \mathrm{kHz}$ and the characteristics were studied by using a Oscilloscope (Fig 7 \& Fig 8).

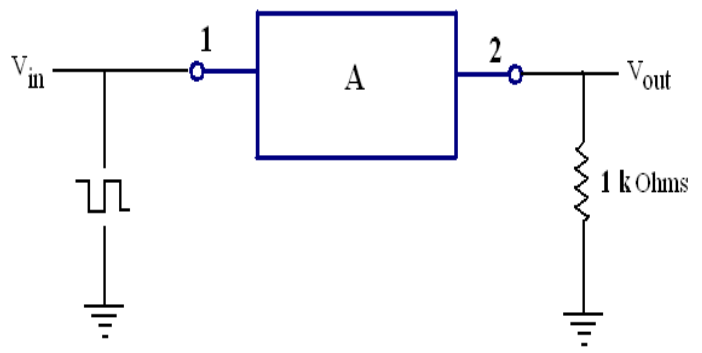

Fig -7: Circuit Diagram I

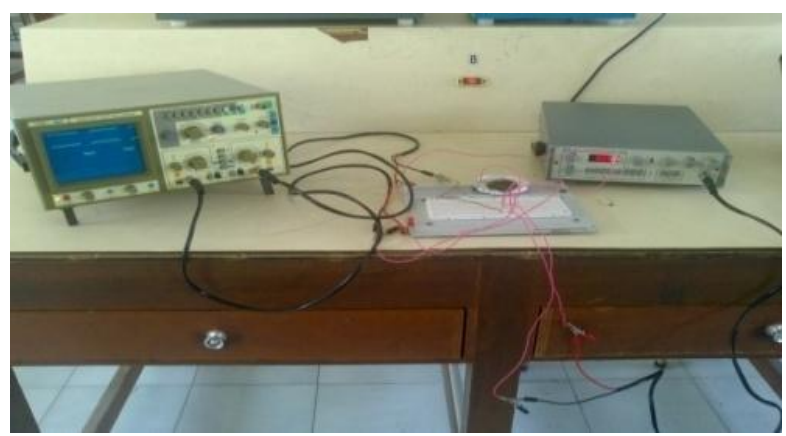

Fig -8: Circuit set-up I

$$
\operatorname{Vin}=-10 \mathrm{~V} \text { to }+10 \mathrm{~V}
$$

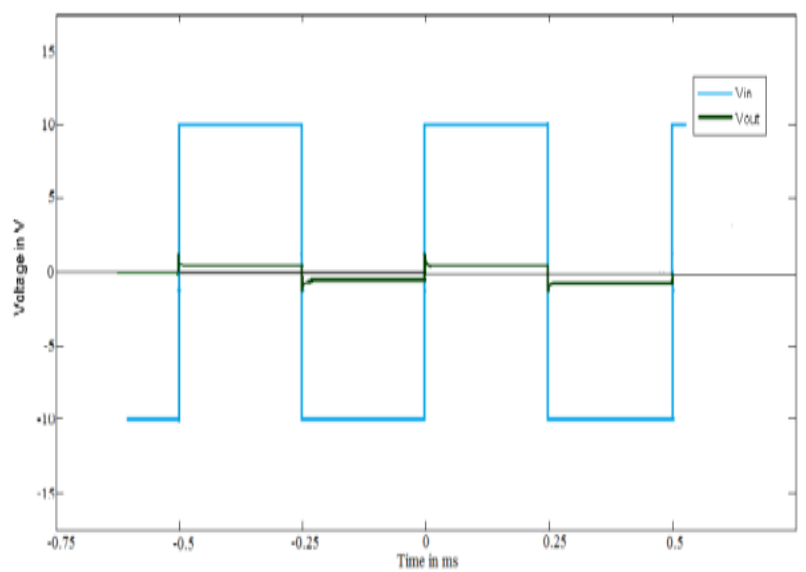

Fig -9: Plot of Vin and Vout of PANI/Ag Schottky diode 
From Fig 9,

$>$ Voltage drop across the diode, $=10 \mathrm{~V}-0.005 \mathrm{~V}=9.9 \mathrm{~V}$.

$>$ Resistance of Diode in forward bias, $=(9.9 / 0.005) * 1 \mathrm{k} \mathrm{ohms}=1980 \mathrm{k} \mathrm{ohms}$

It is to be noted that the resistance being higher, voltage drop across the diode is more and that across the $1 \mathrm{k}$ ohms resistor is more.

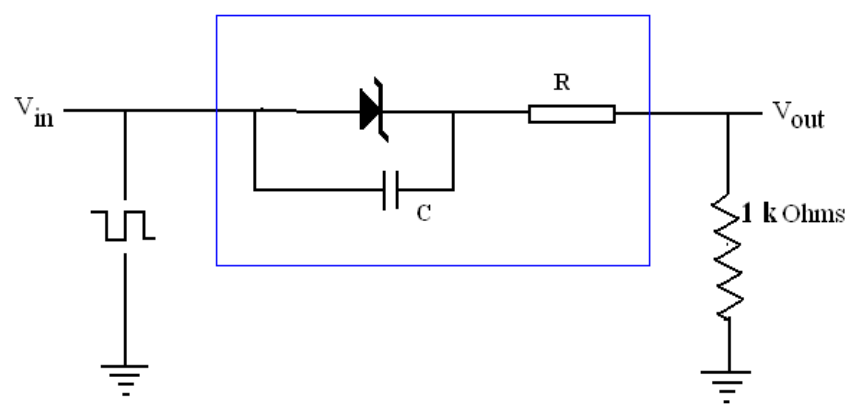

Fig -10: Possible simple equivalent circuit I

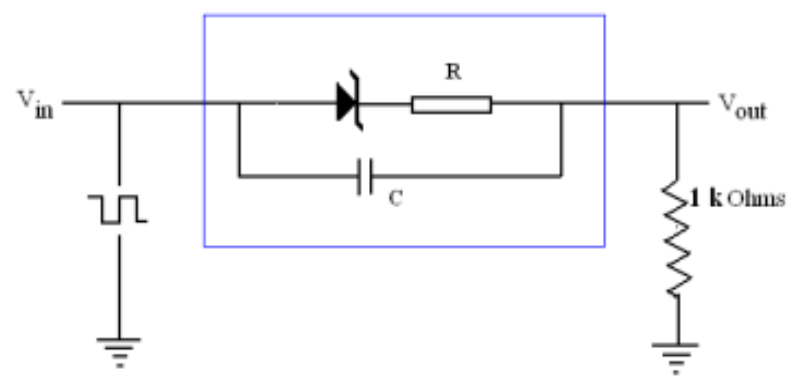

Fig -11: Possible simple equivalent circuit II

$$
\text { Vin }=-9 \mathrm{~V} \text { to }+9 \mathrm{~V}
$$

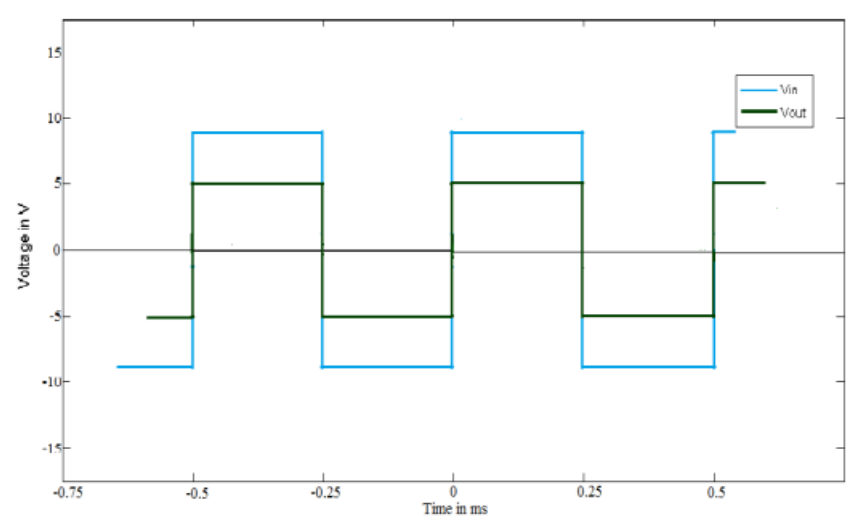

Fig -12: Plot of Vin and Vout of PANI/Ag Schottky diode equivalent circuits
From Fig 12,

$>$ Voltage drop across diode $=9 \mathrm{~V}-5 \mathrm{~V}=4 \mathrm{~V}$

$>$ Thus, diode resistance in forward bias, $=(4 / 5) * 1 \mathrm{k}=0.8 \mathrm{k} \mathrm{ohms}$

Hence from the equivalent circuit I (in forward biased region), we get

By circuit analysis,

$>$ Equivalent resistance $=1.8 \mathrm{k} \mathrm{ohms}$

$>$ Capacitance $\mathrm{C}=\tau / \mathrm{R}=0.27 \mu \mathrm{F}$

Another equivalent circuit II (in forward biased region), is given alongside.

From this, By circuit analysis,

$>$ Equivalent resistance $=(1 * 0.8) /(1+0.8)$ $=0.44 \mathrm{k} \mathrm{ohms}$

Capacitance $\mathrm{C}=\tau / \mathrm{R}=1.125 \mu \mathrm{F}$

\section{CONCLUSIONS}

In brief, we prepared PANI/Ag nanocomposite and analyzed its characteristics by using UV-VIS spectrophotometer. By using this prepared PANI/Ag nano composite, Schottky diode was fabricated. On the other hand, the electrical characterization of Schottky diode using PANI/Ag nano composite was analyzed. The results revealed that the diode has high resistance, low capacitance and low power dissipation. So, it could be used in photovoltaic applications.

\section{REFERENCES}

[1]. David L. Butler, "Low-voltage band gap reference design utilizing Schottky diodes", Boise State University, March, 2005

[2]. Elmansouri,N. Hadik, A. Outzourhit, A. Lachkar, A. Abouelaoualim, M.E. Achour, A. Oueriagli, and E.L. Ameziane, "Schottky Diodes and Thin Films Based on Copolymer: Poly(aniline-co-toluidine)", Hindawi Publishing Corporation, Active and Passive Electronic Components, Volume 2009, Article ID 378086, doi:10.1155/2009/378086

[3]. Elmansouria, A. Malaouib, A. Outzourhita, A. Oueriaglia, A. Lachkarc, N. Hadika, M. E. Achourd, Abouelaoualima, and E. L. Ameziane, "Electrical Properties Of Schottky Diodes Based On Poly(O-Toluidine) Deposited By Spincoating", The Moroccan Statistical Physical and Condensed Matter Society, December 2010

[4]. N. Z. Yahaya, F. H. Ramle, "Simulation and Analysis of Si Schottky Diode Family in DC-DC Converter", International Journal on Electrical Engineering and Informatics -Volume 1, Number 2, 2009

[5]. Mohammed Ahmed Ali, Elias Saion, Noorhana Yahya, Anuar Kassim,Khairulzaman Mohd Dahlan, Shahri Hashim, "Synthesis of conducting polyaniline 
nanocomposites by radiation doping", Journal of Engineering Science and Technology Vol. 2, No. 1 (2007) $111-118$

[6]. M.Angelopoulos, "Conducting polymers in microelectronics", IBM J. RES. \& DEV. VOL. 45 NO. 1 January 2001

[7]. Sindhu Honmute, Sharanabasava V. Ganachari, Ravishankar Bhat, HMP Naveen Kumar Do Sung Huh and Abbaraju Venkataraman, "Studies on Polyaniline-Polyvinyl Alcohol (PANI-PVA) Interpenetrating Polymer Network (IPN) Thin Films", International Journal of Science Research Volume 01, Issue 02, September 2012, pp. 102106

[8]. Y. B. Wankhede, S. B. Kondawar, S. R. Thakare, P. S. More, "Synthesis and characterization of silver nanoparticles embedded in polyaniline nanocomposite", Adv. Mat. Lett. 2013, 4(1), 89-93

[9]. S. AbdulAlmohsin, S.M. AL-Mutoki and Z. Li, "Al/PANIMWNT/Au-Plastic Schottky Diode Solar Cells", Journal of the Arkansas Academy of Science, Vol. 66, 2012

[10]. Scott Milam, "Effects of Silver Nanoparticles on Photochemical Processes Focusing on Luminol Chemiluminescence", Master's Theses and Doctoral Dissertations, January 2010

[11]. Pronob Jyoti Saikia, Pratap Chandra Sarmah, “ Investigation of Polyaniline Thin Film and Schottky Junction with Aluminium for Electrical and Optical Characterization", Materials Sciences and Application, 2011, 2, 1022-1026

[12]. L. Meier, P. Davis, A. Shibata, T. Abc, K. Kinoshita,C. Bishop, S Mahajan, A. Rohatgi, P. Doshi, and M. Finnegan, "Self-doping contacts and associated silicon solar cell structures", World conference and exhibition on photovoltaic solar energy conversion 6-10 July 1998.

[13]. Arnab Dhabal, "Fabrication and Characterization of Schottky Diode", Thesis.

[14]. Eisermann, K. Holl, W. Smetana, W. Tusler, M. Unger, and J. Whitmarsh, "Comparison of low cost, insulated aluminium substrates used as integrated heat sinks with conventional technology”, IMAPS Nordic September 14, 2008

[15]. S.K. Shukla, Anand Bharadvaja, Ashutosh Tiwar, G.K. Parashar, G.C. Dubey, "Synthesis and characterization of highly crystalline polyaniline film promising for humid sensor", Adv. Mat. Lett. 2010, 1(2), 129-134

[16]. Basavaraj udapudi, Praveenkumar Naik, Sabiha Tabassum Savadatti, Rupali Sharma, Samprita Balgi, "Synthesis and characterization of silver nanoparticles", International Journal of Pharmacy and Biological Sciences, (e-ISSN: 2230-7605),2012

[17]. J.Bhadra and D. Sarkar, "Size variation of polyaniline nanoparticles dispersed in polyvinyl alcohol matrix", Bull. Mater. Sci., Vol. 33, No. 5, October 2010, pp. 519-523

[18]. Maribel G. Guzman, Jean Dille, Stephan Godet., "Synthesis of silver nanoparticles by chemical reduction method and their antibacterial activity" ,International Journal of Chemical and Biological Engineering 2:3 2009

[19]. K. Tikhomirov, V. D. Rodriguez, A. Kuznetsov, D. Kirilenko,G. Van Tendeloo, and V. V. Moshchalkov, "Preparation and luminescence of bulk oxyfluoride glasses doped with Ag nanoclusters", OPTICS EXPRESS 22040, Vol. 18, No. 21, 11 October 2010

[20]. K. Zeljami, J. Gutierrez, J. P. Pascual, T. Fernandez,A. Tazon, and M. Boussouis, "Characterization and modeling of Schottky diodes up to $110 \mathrm{ghz}$ for use in both flipchip and wire-bonded assembled environments", Progress In Electromagnetics Research, Vol. 131, 457-475, 2012

\section{BIOGRAPHIES}

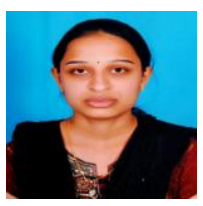

Rohini Dhandapani is currently pursuing M.E (VLSI DESIGN) in Kongu Engineering College, India. She completed her B.E (ECE) at Info Institute of Engineering, Anna University, India. Her major interest is Nanoelectronics.

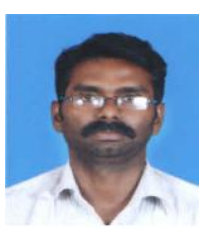

Senthil Kumar Kandasamy is currently working as assistant professor in department of ECE, Kongu engineering college, India. He completed his M.Tech in Nanoscience and technology at KSR College of Technology, Anna university. He has published and presented 9 papers. His major research interests are nanocomposite, supercapacitor and solar cell. 